\title{
A Structural Format to Facilitate User Input for the Co-design of a Cardiac Health Unit
}

\author{
Tanut Waroonkun
}

Faculty of Architecture, Chiang Mai University, Thailand

Received June 21, 2020; Revised August 6, 2020; Accepted August 25, 2020

\section{Cite This Paper in the following Citation Styles}

(a): [1] Tanut Waroonkun , "A Structural Format to Facilitate User Input for the Co-design of a Cardiac Health Unit," Civil Engineering and Architecture, Vol. 8, No. 5, pp. 760 - 770, 2020. DOI: 10.13189/cea.2020.080503.

(b): Tanut Waroonkun (2020). A Structural Format to Facilitate User Input for the Co-design of a Cardiac Health Unit. Civil Engineering and Architecture, 8(5), 760 - 770. DOI: 10.13189/cea.2020.080503.

Copyright $\mathrm{C} 2020$ by authors, all rights reserved. Authors agree that this article remains permanently open access under the terms of the Creative Commons Attribution License 4.0 International License

\begin{abstract}
Experience-based co-design and post occupancy evaluation are two mechanisms adopted for future planning and design of built spaces. They share a common strategy in that they both require input from a prospective, or current, built environment user. In the case of healthcare spaces, these users include doctors, nurses, patients and family. However, obtaining relevant and useful information from these sources is problematic. The users lack any specific conceptual knowledge and skills required in the design process. Several authors have addressed this issue by asking the user to comment on specific healthcare environment variables. These variables are the results of prior evidence-based research. Based on the work of Van der Voort and Van Wegen (2005) the author has developed a survey questionnaire and user input procedure Waroonkun (2019) that addresses the functional elements of a healthcare, built environment (in this case, a cardiac health unit). The strength and impact of this method was its ability to tap into a broad functional view of the users' experience of a built environment. The results of the present study indicate using a POE based, structured assessment strategy provided a solid guideline for determining a wide range of design issues from a user perspective.
\end{abstract}

Keywords Experience-based Codesign (EBCD), Post Occupancy Evaluation (POE), Cardiac Health Unit (CHU)

\section{Introduction}

The Maharaj Nakorn Chiang Mai Hospital is a large public hospital in regional Thailand. The hospital has expanded substantially over its history. Part of this development was the establishment of a Cardiac Health Unit some twenty years ago. The Cardiac Health Unit (CHU) was proposed and built during the period when hospital management adopted an "incremental" approach to development: no forward overall strategy plan [15]. The physical space initially allocated to the cardiac unit was a specific square-footage. Facilities required for the center had to be designed to fit the allocated space. There was no consideration given to sustainability/flexibility, and definitely limited interest in a patient-centered approach to design.

Patients attend the Cardiac Health Unit as outpatients. They are either making an initial enquiry (after referral by a physician) regarding concerns of more serious cardiac problems, or they are attending for follow-up after heart related diagnoses that require monitoring, or they have recently undergone heart surgery and/or pacemaker implant. The limitations of the facility have become obvious. The situation has been exacerbated by the increasing number of patients: a result of increased longevity of the population and the increase in incidence of cardiac problems in the community.

The author was invited to investigate any built-space design issues effecting the efficient functioning of the current CHU. The rationale was to provide comment on any structural changes required, or alternatively, to provide advice on the construction of a new site. To this end, the author has chosen to use an experience-based co-design (EBCD) model. EBCD is a participatory process wherein stakeholders of a service or product have input to its final 
design. Considerable research is now available regarding the use of EBCD in the development of healthcare services [3]. There is, however, limited research discussing the role of EBCD in the design of physical hospital spaces.

Based on a model developed by Bate and Robert (2007) researchers (healthcare services) have sought stakeholders' input using surveys, interviews, and focus groups. EBCD research regarding hospital services and architectural issues has involved input from nurses, doctors, and patients as "participators" in the healthcare environment. After an initial individual survey, the various groups come together to finalize an approach to service design that all agree would be mutually beneficial. However, when deciding on architectural design rather than healthcare service procedures, there is a different focus for the EBCD process. Building design issues require stakeholders to comment on their experience with their physical built environment rather than service provision. Further, the EBCD model requires stakeholders, in the final phase, to share the results of their focus group deliberations with design professionals.

Researcher comments have suggested that input from stakeholders is limited by their lack of experience with the design process. This current study aims to address this issue. For the design team the question is: What information do we get from the stakeholders? How can we ensure this information is successfully considered as input for the final design? An important source of information about a designed physical space is the post occupancy evaluation (POE). The POE process, inter alia, assesses the functionality of the built space. Here functionality addresses the question: Does the building do what it was designed for in an effective and efficient way [5]. Van der Voordt and Van Wegen (2005) argue that the 'functionality' of a built space can be measured in terms of nine elements: reachability, accessibility, efficiency, safety, spatial orientation, privacy, health and well-being, interior climate, and sustainability.

In assessing the functionality of the current cardiac health unit, the author has selected certain of the above elements as a basis for user input. Requiring stakeholders to think about their experiences and describe them in this structured format will minimize the problems of lack of experience and expertise in providing useful input. A structured assessment of stakeholder experience that is based on an architectural model will help focus user thinking and further provide information that is relevant to designers.

The aim of this study is to determine if a structured model for assessing user input will provide more relevant information for the final stage of the EBCD process involving interaction with design professionals. The need is to provide a guideline for information gathering that will enhance the quality and relevance of information available from stakeholders. Although there have been other methods of categorizing this information, the author argues that a structure that is already part of the building evaluation process will be more successful. Using the categories for building functionality suggested by Van der Voort and Van Wegen (2005), as a guideline, will make it easier for users to organize their thoughts about their experiences. The users can then provide a more focused opinion regarding their perception of the current $\mathrm{CHU}$ space and provide comment for any new design. Further, the information forthcoming will be more synchronous with the conceptual thinking of designers and thereby enhance any subsequent interaction between users and design professionals.

The outcome of this study will provide a model for assessing stakeholder input for the final stage of the EBCD process, wherein the design professional seeks input from users of a built environment.

\section{Background}

The current Cardiac Health Unit (CHU) at Maharat hospital was established some twenty years ago. Historically, the hospital has used an "incremental space adaptation strategy" for continuing development [15]. Incrementalism is an approach to development that is used when there is a need for rapid expansion of physical facilities. At the time there was a perceived need for a cardiac health unit. The physical space initially allocated to the proposed unit was a specific square-footage. Facilities required for the center had to be designed to fit the allocated space. There was no consideration given to sustainability/flexibility, and definitely limited interest in a patient-centered approach to design. Hospital design was, at that time, based on the requirements of medical specialties as opposed to concern for the patient [10]. The current cardiac health unit layout is shown in Figure 1.

For the purposes of this study, in terms of public and private space, the physical space allocated to the CHU has been categorized as three separate zones; medical staff areas; medical examination area, and waiting (public) area. Medical staff areas are places that are off-limits to the general patient population, and consist of rooms used by doctors and nurses in their organizing and administrative roles. Medical examination areas include specific medical examination rooms: echocardiogram, ECG, exercise stress test, pacemaker review, congenital heart disease monitoring, and general diagnostic interview room. Entry to these areas is at the behest of medical staff. Waiting area includes those public spaces that patients may freely use. (See Figure 1).

The proposed experience-based co-design (EBCD) model to be used in this study is a participatory process, involving active input from medical staff and patients. Bate and Robert (2006) suggest a basic model for EBCD as a multi-stage process. The initial step requires the gathering of information from stakeholders as individuals. Individual 
profiles are then analyzed and shared with members of the specific participant group. The different participating groups come together to share experiences, and through various strategies, decide on recommendations for change. Most healthcare research using EBCD, to date, has focused on the re-design of procedures and services [3]. There has been little discussion of its use in the analysis of healthcare facilities (built environment). This current study focused on user opinions about the built structure of a hospital clinic rather than the services provided.

Waroonkun (2019) when investigating nursing staff input to the design of a new outpatient department, proposed a modified model of EBCD. Essentially this model includes a final stage where the user groups meet with design specialists and jointly develop a working outline for a potential design for a new, or revised, facility. A more complete version of the model is shown in Figure 2. Fay, Carll-White and Harrell (2016) also argue for the use of a final charrette, wherein user input has a significant role in design outcome. The charrette process is seen as a concrete way to apply the results of a post-occupancy evaluation.

Prior research has identified a number of limitations when using the EBCD and POE strategies to elicit user input. A consistent observation relates to the difficulty users experience when asked to comment on an issue (building design) where they have limited conceptual knowledge or experience $[8,10,16]$. Jellema, Annemans and Heylighen (2019) suggests that, when examining the role of architecture, most individuals would have difficulty describing how they experience a 'space'. In an attempt to resolve this problem, several authors concerned with design of physical spaces have provided initial user surveys based on a number of macro environmental categories.

There is a recognized relationship between a hospital's-built environment and patient healthcare outcomes $[13,14]$. This necessitates that any assessment of the hospital environment includes environmental variables that are known to have such an impact. Fay, Carll-White and Harrell (2016) have argued that any such variables must result from extant evidence-based research. In an assessment of a hospital Emergency Department they surveyed staff, visitors, and patients seeking comment on built environment design variables. Their survey instrument included core questions related to audio environment, visual environment, safety enhancement, wayfinding systems, treatment rooms, family support spaces, staff support spaces, privacy, and communication. In an extensive review of POE assessment tools, Brambilla and Capolongo (2019) found that most POE assessment tools, used in hospital/clinic environments, have a strong emphasis on healthcare variables and sustainability. The healthcare variables included: safety enhancement, visual environment, audio environment, staff and doctor space features, patient room features, wayfinding features, family/visitor space features, and sustainability. Waroonkun (2019) used survey items drawing on evidence-based design literature and healthcare environment research. Nursing staff feedback regarding an outpatient department was assessed for several categories: workplace layout (physical layout of space), safety (both nursing staff and patients), general ambience (lighting, noise, greenery, color), privacy (staff and patient), and convenience facilities (canteen, etc.).

Experience based co-design is equivalent to post-occupancy evaluation (POE) in as much as they both aim to improve future building design using some form of input from intended users. Post Occupancy Evaluation (POE) has been defined by several authors $[2,4,5]$. Essentially, POE asks: Does the built structure achieve the purpose for which it was designed? What is the inter-relationship between the built environment, user experiences (e.g. patients, doctors, nurses), and operational outcomes of the building? [9]. How does the building performance compare with user expectations? [1]. Van der Voort and Van Wegen (2005) argue that POE deals with the "functional quality" of the building. Functional quality "requires a building [built space] to have good accessibility, to provide sufficient space, to be arranged efficiently and comprehensibly, to be sufficiently flexible, and to provide spatial and physical conditions that will ensure a safe, healthy, and pleasant environment" (p.4). They further argue that the functional quality of a building can be evaluated by considering nine specific criteria: reachability, accessibility, efficiency, flexibility, safety, spatial orientation, privacy, health and physical well-being, and sustainability.

The objective of the EBCD in this study is to improve the design outcome for a new cardiac health unit, as part of a hospital environment, using input from prospective users. Providing comment regarding built environment design variables is somewhat beyond the knowledge and experience of medical professionals and patients [12]. Thus, a guiding structure that can facilitate opinion regarding the built environment is desirable. The instrument developed for this study was based on the elements of 'functionality' as defined by Van der Voort and Van Wegen (2005) [4]. The macro areas of the instrument were also linked to extant healthcare environment variables based on evidence-based literature search. This instrument differs from other measures in that it prioritizes the 'functionality' characteristics of a built environment over healthcare related issues. The instrument thus caters for lack of user knowledge and expertise, includes health related concepts, and links to building functionality as an integral aspect of post-occupancy evaluation.

As the current study relates to a defined space (CHU) within the hospital building, it was limited to considering only the following functionality elements:

- Accessibility: ease with which users can enter the space and use rooms and services intended for them.

- Efficiency: optimum support for anticipated activities, includes spatial layout, dedicated areas, ease of cleaning and maintenance. 
- Safety: especially user safety, must cater for all potential users considering strength, mobility, handicaps. Need to consider environmental factors; e.g. floor surfaces, adequate lighting, management of space, no sharp edges or corners.

- Spatial Orientation: understandable layout: e.g. recognizable functional units, clear distinction between public and private areas; clear and comprehensible signage; organizational measures: reception/information areas.

- Privacy: visual: control over whether to be seen or not (examination room); auditory: not disturbed by noise of others, confidential communication not overheard by others; social/ territorial control over need to be "private"; control over levels of social contact.

- Health and well-being: light (daylight, suitable intensity, reflective surfaces, color); noise (no irritating noises-especially in cardiac stress situations); interior climate: room temperature-avoid extremes; ventilation-removal of uncomfortable odors; control of humidity

Using these criteria as part of an assessment regime, stakeholders can give a more focused opinion regarding their perception of the current CHU space and indicate preferences for inclusions or modifications in any new designs.

\section{Materials \& Method}

The research proposal was presented to Hospital Management and the Senior Cardiac Registrar. Approval was granted on the condition that nursing staff were consulted prior to selection of patient participants.

\subsection{Participants}

Participants in this study were drawn from three distinct groups of users of the CHU: patients, nursing staff, and medical practitioners. Each participant was approached individually to invite their involvement in the study. The three-stage process (survey, focus group, and joint working group) and the participant's potential involvement were fully discussed. Within the 'Doctor" group several medical professionals declined to be involved, citing 'busy schedule' as the reason. Nursing staff were keen to be involved. Patients were initially screened by the research team (with the advice of the Senior Nurse) before they were approached. Very elderly patients and those with more serious cardiac issues were not approached (this may have some repercussions regarding the 'representativeness' of the sample, but the author was prepared to err in favor of patient welfare). Further, given the difficulty for patients to attend the hospital (travel times, transport availability), only those patients who were scheduled to attend the CHU on a future date were approached

\subsection{Survey Instrument}

A survey questionnaire was designed to elicit participant feedback about various aspects of the CHU built space. The space was considered as three functional units: waiting area (public), examination area (public/private), and medical staff area (private). The survey items were based on the elements of a functional analysis (as part of a POE) of a built environment. More particularly six macro areas were selected as being suitable for this study: accessibility, efficiency, safety, spatial orientation, privacy, and health and well-being [4]. In deference to prior evidence-based research of hospital environments [14] questions items about "greenery" and artwork were also included in the survey. Participants were asked to rate their level of agreement for individual items related to a particular macro element. The survey used a Likert format, where respondents score ' 1 ' meaning 'strongly agree' through to ' 5 ' meaning 'strongly disagree'. A score of ' 3 ' represents a 'neutral' response - no committed feeling either way. A mean score and standard deviation were calculated for each item. Patient views on medical staff areas were not elicited as those areas are not relevant to patient use. This necessitated the development of two survey forms: items regarding the medical staff area were absent from the 'patient version' of the survey questionnaire. The language used for the survey instrument was Thai. Translations have been made for this report.

\subsection{Process}

Phase 1 (Survey Completion): Participants were first given the survey form to be completed individually at the hospital and returned to a member of the survey team on completion. Survey team members were on hand to deal with any problems, otherwise the results were confidential. The survey results were tabulated for each group and a copy was sent to each member of their group. Participants were asked to review their group's results and think about the reasons for their own responses. The report and their thoughts would be part of a group discussion in the next phase of the study.

Phase 2. (Focus Group): Members of each participant group met as a distinct 'focus group' (doctors, nurses, and patients). A future date for each focus group had been arranged and participants were asked if they could attend on that date. For patients, the cardiac unit was able to schedule future appointments so that patients would be free to participate (medical consultation in the morning and research post-lunch afternoon. A free lunch was provided by the hospital). For doctors and nurses, management agreed to cover participants' time off by rostering extra staff for that period.

In each focus group session participants were given a copy of their respective group's survey profile again. Focus groups met in the CHU meeting room (quiet, private space, seating for twenty people). The focus group facilitators 
were members of the research team who had undergone a short course on focus group management. All facilitators had previous focus group experience [18]. After initial introductions and explanation of the purpose of the focus group, the facilitator-initiated discussion using the survey macro elements as a discussion structure. The opening question in each case was, "What are your thoughts on the items related to factor X". The group was encouraged to express their views freely. The facilitator explained there was no 'correct' answer and that all thoughts, ideas, suggestions were valuable.

Audio recordings of each focus group were kept for later analysis. Major themes and common ideas about each element were assessed and noted. At the close of the focus group discussion each group was asked to nominate three members to participate in a Joint Working Group (Phase 3). Results of the Phase 2 focus groups were sent to all members of the Joint Working Group (JWG) prior to its meeting.

Phase 3 (Joint Working Group): Because of the small number of participants in each user group, the 'joint group sessions' stage of the model (Fig. 1) was omitted. A joint working group (JWG) made up of three members of each of the three participating user groups was established $(\mathrm{N}=9)$. The JWG met in the same venue as Phase 2. Each of the participants was again given a copy of the Phase 2 focus groups' discussion profiles. The research team leader (author) was present at this session initially. He explained the objective of this session to the group: to provide their thoughts on the current $\mathrm{CHU}$ built area with a view to making design adjustments in the future. The author stressed that the discussion was "not just an academic exercise" but that a future design team would be keen to know "what works and what doesn't". Again, the facilitator opened the session with an introduction phase, an explanation of the purpose of the session, and an opening question. As for phase 2, discussion was based on the macro elements from the survey. The joint working group was asked to discuss issues raised in the Phase 2 focus group sessions. As a result of their discussion they were asked to compile a list of suggestions and recommendations for the re-design of the current $\mathrm{CHU}$ or the design of a new CHU. The JWG session was recorded and later analyzed and summarized. The report of the recommendations and their rationale would provide the input for later discussion with design professionals.

\section{Results}

Participants in the study were drawn from one of three groups (Doctors, Nurse, and Patients). The number of doctors available to the Cardiac Health Unit is ten. In order that no one group dominated the study, the number of participants was held at ten for each group $(\mathrm{N}=30)$

Doctors: the doctor group $(\mathrm{N}=10)$ consisted of eight (8) males and two (2) females. Three (3) were senior cardiac consultants, the remaining seven (7) were cardiac registrars. All physicians had at least five years' experience as a cardiac specialist and three years working in the hospital CHU.

Nurses: all of the nursing group $(\mathrm{N}=10)$ were female. All participants had at least two years' experience in the cardiac unit.

Patients: Patients in the study $(\mathrm{N}=10)$ were male $(\mathrm{N}=4)$ and female $(\mathrm{N}=6)$. Age range for patients $21-40$ years $(\mathrm{N}$ $=3), 41-60$ years $(\mathrm{N}=5)$, over 60 years $(\mathrm{N}=2)$. Many elder patients were excluded from the study as a result of selection conditions applied.

Survey results are displayed in Table 1 . For each item the participants indicated their level of agreement with the item statement. A low-level score $(<3)$ shows general agreement with the statement. A high-level score $(>3)$ indicates a level of disagreement. A score of ' 3 ' represents a 'neutral' response. A detailed analysis follows:

Doctors: Survey results for doctors suggest doctors have little concern about the CHU built area in general. They have three areas of concern: the amount of space available in the examination room (Item 2.3, $\overline{\mathrm{x}}=4.1$ ), and in the medical staff area (Item 2.4, $\overline{\mathrm{x}}=3.9$ ), and there was some concern about movement within the CHU space in general (Item 2.6, $\bar{x}=3.9$, Item 3.7, $\bar{x}=3.8$ )

Nurses: Nurse survey profile suggests several areas of critical concern. Accessing areas within the treatment area is of concern (see survey items $1.4,1.5,1.6$ ). In terms of building efficiency, nurses have concerns regarding all aspects (items): waiting area, examination area, and general workflows within the space. This is reflected also in nurses' opinion regarding the demarcation of spaces (Item 5.2, $\bar{x}=4.1$ ). They had an issue with safety in areas used by patients (Items 3.1 and 3.2), and also about general movement in the CHU (Item 3.7, $\overline{\mathrm{x}}=4.1$ ). Nurses shared patients' concern for privacy in areas where staff/patient interaction occurs (Items 4.1, 4.2, 4.3). Nurses felt there was limited suitable space for confidential discussion in the medical staff area (Item 4.4).

Patients: Patients concerns related to accessing the examination rooms within the CHU (Item 1.4, $\bar{x}=3.7$ ). They expressed concerns about space and facilities in the waiting area and examination room (Items 2.1, 2.2, 2.3). Privacy issues were also registered as sources of dissatisfaction (Items 4.1, 4.2, 4.3). The general layout of the CHU was seen as confusing for patients (All items for "Spatial Orientation"). The ambience ("well-being" element) of the CHU was generally acceptable but with some concerns about the noise level in the waiting area (Item 6.4), and the temperature in the examination room (Item 6.2). In terms of aesthetics, patients felt that the inclusion of some type of greenery is appropriate (Item 6.13). That view was not shared regarding the introduction of artwork/photos. Overall patients did not feel at ease in the CHU (Item 6.15) 


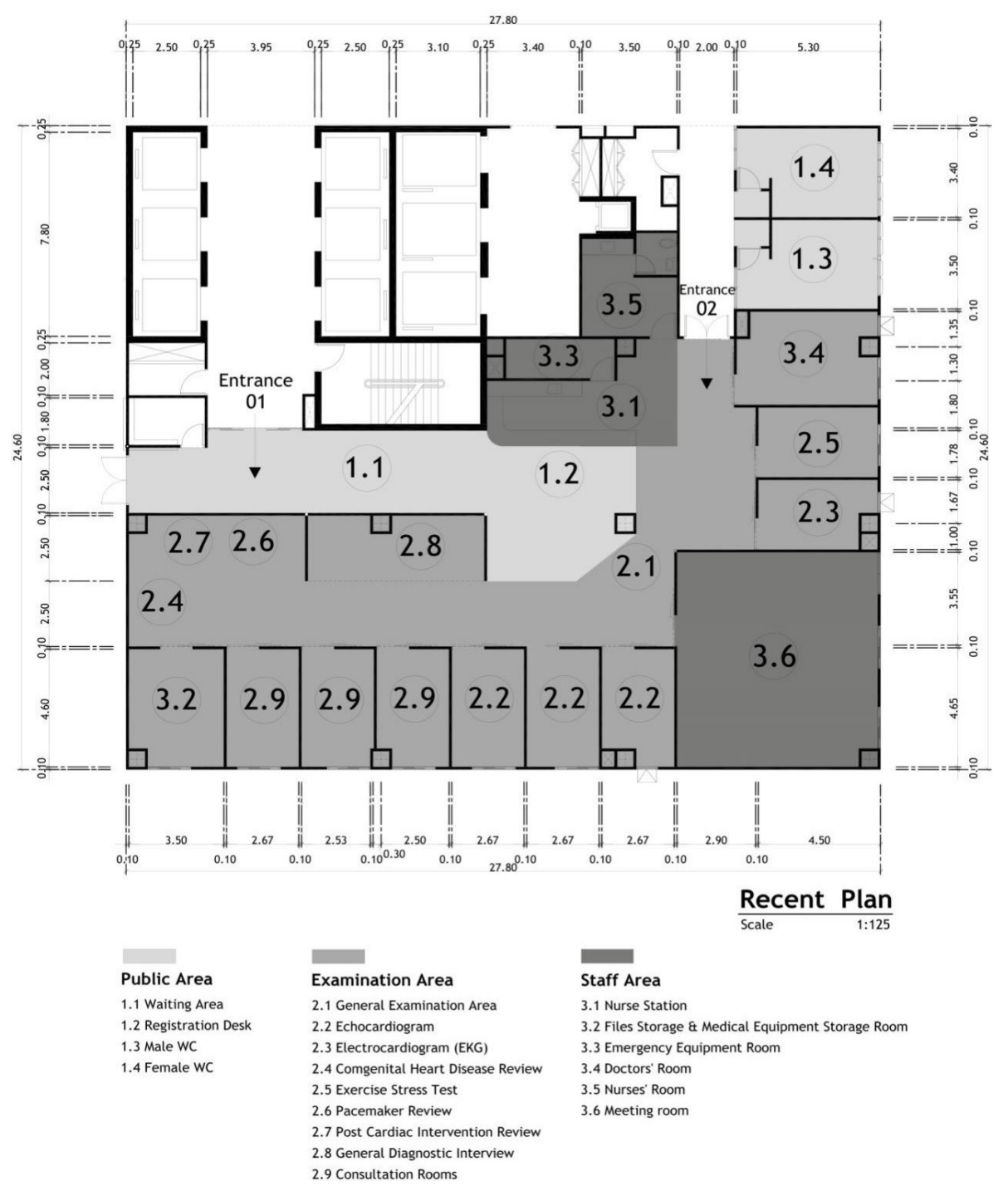

Figure 1. Floor plan of the current Cardiac Health Unit

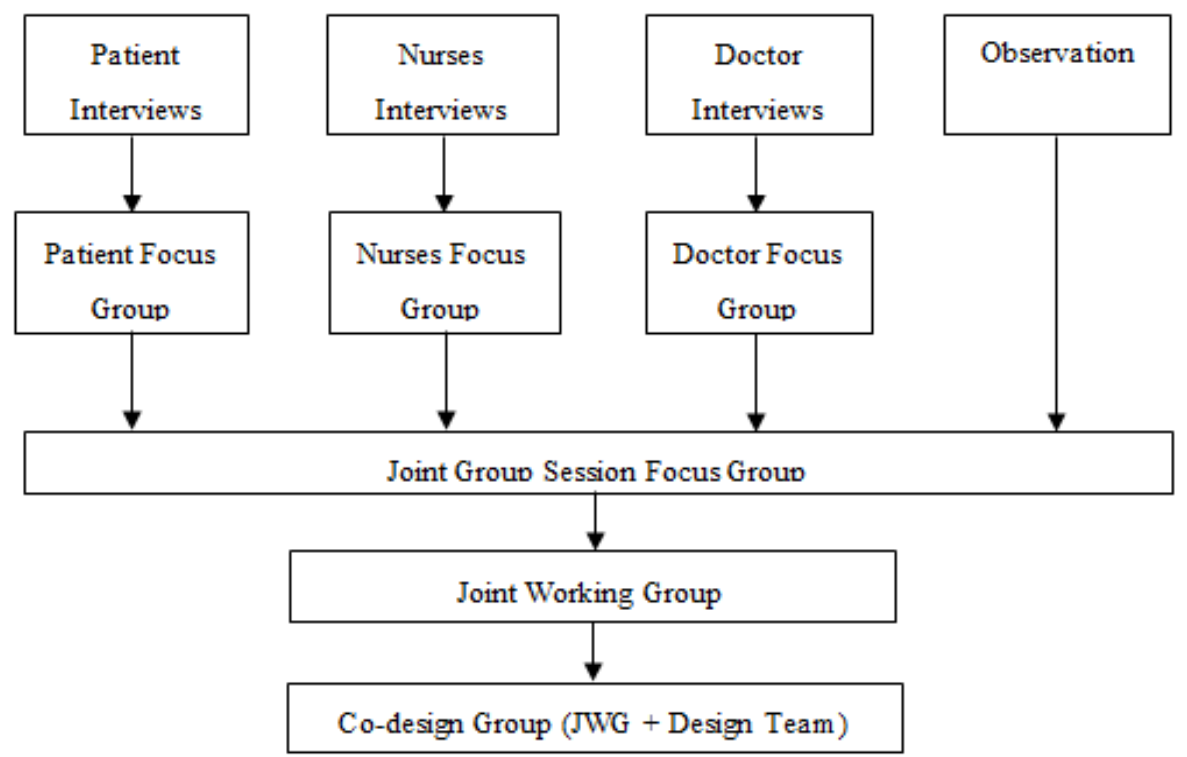

Figure 2. A more detailed version of the EBCD model 
Table 1. Questionnaire Responses

\begin{tabular}{|c|c|c|c|c|}
\hline POE Element & Item & $\begin{array}{c}\text { Doctors } \\
\text { Mean } \\
\text { (SD.) }\end{array}$ & $\begin{array}{c}\text { Nurses } \\
\text { Mean } \\
\text { (SD.) }\end{array}$ & $\begin{array}{c}\text { Patients } \\
\text { Mean } \\
\text { (SD.) }\end{array}$ \\
\hline \multirow[t]{7}{*}{ Accessibility } & 1.1 Entry to the CHU is easy to find and use & $1.5(0.52)$ & $1.4(0.51)$ & $2.6(0.51)$ \\
\hline & 1.2 Getting to the Registration Desk is easy & $2.5(0.51)$ & $3.6(0.70)$ & $3.2(0.63)$ \\
\hline & 1.3 The waiting area is easy to find & $1.5(0.52)$ & $2.5(0.53)$ & $3.2(0.63)$ \\
\hline & 1.4 Moving to the examination room is easy and unobstructed & $3.4(0.52)$ & $4.3(0.67)$ & $3.7(0.67)$ \\
\hline & 1.5 Accessing the medical staff area is easy and unobstructed & $3.0(0.47)$ & $4.1(0.74)$ & N/A \\
\hline & 1.6 Wheelchair access to all areas is easy & $3.2(0.42)$ & $4.0(0.67)$ & $2.9(0.57)$ \\
\hline & 1.7 The CHU has a welcoming feel & $2.5(0.70)$ & $2.8(0.91)$ & $3.1(0.74)$ \\
\hline \multirow[t]{6}{*}{ Efficiency } & 2.1 Waiting area has sufficient space for its intended use. & $3.3(0.48)$ & $4.5(0.52)$ & $4.0(0.94)$ \\
\hline & 2.2 Waiting area has enough facilities (chairs, water, etc.) & $3.4(0.51)$ & $4.2(0.78)$ & $4.0(0.82)$ \\
\hline & 2.3 Examination room has enough space for use and equipment. & $4.1(0.73)$ & $4.4(0.70)$ & $3.7(0.67)$ \\
\hline & 2.4 Medical staff areas have enough space for function and equipment & $3.9(0.57)$ & $4.4(0.70)$ & N/A \\
\hline & 2.5 Medical equipment is easily available when needed. & $3.3(0.48)$ & $4.5(0.52)$ & N/A \\
\hline & 2.6 Moving to different areas of the CHU is easy and unobstructed & $3.9(0.57)$ & $4.1(0.57)$ & $4.0(0.67)$ \\
\hline \multirow[t]{7}{*}{ Safety } & 3.1 Waiting area provides a safe environment for all users & $3.1(0.57)$ & $3.9(0.74)$ & $3.7(0.82)$ \\
\hline & 3.2 Examination rooms provide a safe environment for all users & $3.2(0.42)$ & $3.8(0.79)$ & $3.3(0.48)$ \\
\hline & 3.3 Medical staff areas provide a safe environment for all users & $3.0(0.67)$ & $3.0(0.67)$ & $\mathrm{N} / \mathrm{A}$ \\
\hline & 3.4 Internal equipment and furnishings use a safe design and materials & $2.8(0.42)$ & $3.2(0.63)$ & $2.5(0.53)$ \\
\hline & 3.5 CHU is a safe environment for wheelchair and disabled people. & $2.5(0.53)$ & $3.2(0.63)$ & $2.6(0.70)$ \\
\hline & 3.6 Emergency safety equipment is visible and easily reached & $2.5(0.53)$ & $2.0(0.67)$ & $2.6(0.51)$ \\
\hline & 3.7 Moving about in the CHU is safe and unobstructed. & $3.8(0.79)$ & $4.1(0.57)$ & $3.8(0.63)$ \\
\hline \multirow[t]{5}{*}{ Privacy } & 4.1 Conversation with nursing staff at registration is private & $2.8(0.63)$ & $4.1(0.74)$ & $4.2(0.63)$ \\
\hline & 4.2 People outside could easily see the patient in the examination room & $3.4(0.51)$ & $2.4(0.51)$ & $2.0(0.67)$ \\
\hline & 4.3 People outside can hear conversations in the examination room & $3.9(0.74)$ & $2.7(0.95)$ & $2.4(0.70)$ \\
\hline & 4.4 The medical staff area provides sufficient privacy and security & $2.9(0.74)$ & $3.9(0.74)$ & $\mathrm{N} / \mathrm{A}$ \\
\hline & $\begin{array}{l}\text { 4.5 In the CHU I felt I have control of how I made contact with other } \\
\text { people }\end{array}$ & $1.5(0.53)$ & $2.0(0.67)$ & $3.5(0.53)$ \\
\hline \multirow[t]{6}{*}{$\begin{array}{c}\text { Spatial } \\
\text { Orientation } \\
\end{array}$} & $5.1 \mathrm{In}$ the $\mathrm{CHU}$ it was easy to see where the patient had to go next & $1.0(0.0)$ & $1.0(0.0)$ & $3.8(0.79)$ \\
\hline & 5.2 The separate 'Public' and 'Medical' areas are clearly defined & $1.5(0.53)$ & $4.1(0.74)$ & $4.3(0.67)$ \\
\hline & 5.3 Different sections in the $\mathrm{CHU}$ had clear and understandable signs & $2.4(0.97)$ & $3.6(0.70)$ & $4.2(0.63)$ \\
\hline & 5.4 The arrangement of rooms in the $\mathrm{CHU}$ is confusing & $4.1(0.89)$ & $4.2(0.79)$ & $2.3(0.95)$ \\
\hline & 5.5 Moving from one section to another in the $\mathrm{CHU}$ is confusing & $4.6(0.52)$ & $4.4(0.70)$ & $2.5(0.85)$ \\
\hline & 5.6 Waiting area is set up so that patients can sit together with family & $3.1(0.57)$ & $3.8(0.63)$ & $4.3(0.82)$ \\
\hline \multirow[t]{15}{*}{ Well-being } & 6.1 The temperature in the waiting area is comfortable & $2.4(0.52)$ & $3.0(0.67)$ & $2.9(0.74)$ \\
\hline & 6.2 The temperature in the examination room is comfortable & $3.3(0.48)$ & $3.0(0.67)$ & $3.7(0.67)$ \\
\hline & 6.3 The temperature in the medical staff area is comfortable & $2.8(0.42)$ & $3.0(0.67)$ & N/A \\
\hline & 6.4 The noise level in the waiting area is annoying. & $3.3(0.48)$ & $2.4(0.70)$ & $2.4(0.52)$ \\
\hline & 6.5 The noise level in the examination room is annoying. & $3.5(0.53)$ & $3.3(0.48)$ & $3.2(0.79)$ \\
\hline & 6.6 The noise level in the medical staff area is annoying. & $4.1(0.74)$ & $4.0(0.82)$ & N/A \\
\hline & 6.7 There is good lighting in the waiting area & $2.5(0.52)$ & $3.2(0.63)$ & $3.1(0.57)$ \\
\hline & 6.8 There is good lighting in the examination room & $2.4(0.52)$ & $2.8(0.42)$ & $2.5(0.53)$ \\
\hline & 6.9 There is good lighting in the medical staff area & $1.3(0.43)$ & $1.6(0.70)$ & N/A \\
\hline & 6.10 The ventilation in the waiting area is good - fresh air, no smells & $2.1(0.88)$ & $2.2(0.79)$ & $2.8(0.42)$ \\
\hline & 6.11 The ventilation in the examination area is good - fresh air, no smells & $2.3(0.68)$ & $2.7(0.48)$ & $2.8(0.42)$ \\
\hline & 6.12 The ventilation in the medical staff area is good - fresh air, no smells & $2.1(0.74)$ & $2.6(0.70)$ & $\mathrm{N} / \mathrm{A}$ \\
\hline & 6.13 There should be plants or 'greenery' in the waiting area & $2.9(0.57)$ & $2.8(0.63)$ & $2.2(0.79)$ \\
\hline & 6.14 Pictures on the wall would make the waiting area more relaxing & $3.0(0.00)$ & $2.9(0.74)$ & $3.1(0.74)$ \\
\hline & 6.15 Overall, I felt comfortable using the CHU & $1.5(0.53)$ & $3.1(0.74)$ & $3.7(0.67)$ \\
\hline
\end{tabular}




\subsection{Focus Groups}

The above survey results provided the basis for discussion during the participant specific (doctor, nurse, patient) focus groups. Focus group input disclosed more detail regarding issues raised in the survey questionnaire. The time spent on this initial focus group discussion varied. Doctors completed their discussion in twenty minutes. Nurses spent more time together; discussing issues for about an hour. Patients were slow to start conversation among themselves but as confidence with the situation grew so did discussion. Patients spent some seventy minutes "chatting" together.

Doctors: Results of discussions suggest the main concern for doctors is the amount of space available. The medical examination areas are too cramped when medical personnel, equipment, and persons accompanying patients all require access to the space. This crowding is also a safety issue when moving about the CHU. The medical staff areas of concern for the doctors were the area set aside for doctors to write reports and to interact with nursing staff on confidential matters. Doctors found the CHU set up (design) to be workable for them. They had no issues with the general physical ambience of the unit.

Nurses: Nurse focus group was a dynamic and engaging session. All nursing staff made considerable input to the discussion. The fundamental concerns were accessing work areas and the lack of available space to perform their duties efficiently. The lack of storage space for equipment etc. resulted in access and flow areas being used for storage, thus causing obstructions and time wasted. The location and size of the storage area was a significant issue. Equipment storage space was not sufficient and accessing equipment (and patient records from the same space) mean traversing an obstacle course between storage room and destination. The fact that "public" and "medical" space are not clearly defined meant that equipment and patients awaiting access to exam room were located wherever space was available. Nurses were concerned about the level of privacy in their professional and patient interaction conversations. Because of space issues and overcrowding in examination room areas, they also had concerns about patient's visual privacy. A particular item of "irritation" was a noisy air conditioning unit above the patient registration area that made it difficult to hear and be heard (a maintenance issue)

Patients: Patients generally found the experience in the CHU lead to anxiety and confusion. Patients' experience in the waiting area: cramped seating - or no seating, lack of flexibility in seating arrangements (especially if patient was in a wheelchair), lack of amenities at or nearby, added to patients' initial anxiety levels. Notwithstanding prior experience in the unit, the lack of appropriate signage and confusing layout was a cause of concern. Reflecting a theme from the nurses, patients were also concerned about the lack of privacy in the waiting area, at the registration desk, and in the examination room. They felt that visual (and to some extent auditory) privacy was lacking. General ambience of the space was acceptable. However, there was comment about temperature regulation in the exercise stress test room (too hot and no breeze). Elderly patients found the waiting area too noisy and worried that they would not be able to hear when their name was called. On the issue of lighting, the absence of windows and natural light was never raised (The current $\mathrm{CHU}$ space has no windows).

\subsection{Joint Working Group}

The Joint Working Group (JWG) was made up of nine people in total. The members of the JWG were selected by their peers in their focus group. Doctors (3) were all male, and junior registrars. The doctor representatives were 'volunteered' by the senior physicians. The nurses (3) were all female and represented different levels of experience at the CHU. Nurses chosen were considered by their group to be experienced nurses and confident speakers. Patient members (3) were one male (41-59 years age group) and two females (41-59 years age group, $60+$ years age group). Patients were chosen because of their experience in the CHU (multiple visits) and their confidence to speak up. The joint working group session was slow to start initially. There was some concern about communication between people of perceived different social status. However, after one of the senior patients spoke openly and frankly, the group warmed to each other and began to act like a team on a mission. The time taken for a final output by the group was nearly three hours (include coffee break).

The discussion agenda for the JWG was based on the elements of functionality as used in the original survey. Generally, the members of each focus group were supportive of one another's focus group discussion points. Results of the joint group discussion are reported below.

Access: The public area entrance is not wide enough to enter for wheelchairs and gurneys, especially as the entrance is through a crowded waiting area. The central area of the CHU and access to the examination rooms is often blocked by equipment and/or patients waiting for assessment. The medical equipment and records storage area location means nurses have obstructed access to this area.

Efficiency: The waiting area lacks sufficient space for current use, has insufficient seating and little potential to arrange furniture to cater for special users (e.g. family with wheelchair patient). There is insufficient space in the medical examination rooms to accommodate equipment, medical personnel, and patient group. There is a lack of specific rooms for some types of assessment, that by default, are conducted in open space (e.g. Fig.1, areas: 2.4, $2.6,2.7)$. Location of registration counter in the central area leads to overcrowding and obstructions. There is limited 
dedicated space (room) for doctors and nurses to complete paper work and converse about medical/patient matters. There is no specific dining and relaxation area for medical staff. The meeting room is essential (teaching hospital) and is suited for purpose.

Safety: All areas where the public are involved, lack several safety installations appropriate to CHU clientele e.g. hand rails, non-slip floors, seating with armrests.

Spatial Orientation: The CHU lacks sufficient space for its effective functioning resulting in overcrowding and obstructions. The layout of the unit is confusing for patients in terms of location of specialist sub-units. The storage room is located at the furthest point from where equipment or records are required. Movement from the waiting area to the toilets means patients must traverse the central function area of the CHU. Adding to the confusion is the considerable overlap between "public" and "restricted area". There is no clear signage displayed.

Privacy: Seating in the waiting area is cramped, making it difficult to organize a 'family unit', thus it is near impossible for patients and family to have a private conversation. Patients in the examination rooms are clearly visible to people in the central area (which often includes other patients waiting outside the examination room). Conversations between patient and medical staff can be heard by others. This is especially the situation at the registration counter.

Well-being: The general ambience of the CHU was considered basically acceptable. The temperature in exam rooms needs local control so it can be adjusted according to room usage. The ambient noise in the unit can reach a high level. The group agreed that this was simply caused by the presence of large number of people accessing and involved in the unit.

The final broad overall comment from the group indicates several areas to be considered in future designs. Many of the problems are the result of overcrowding due to lack of space. The second point of concern was the poor layout of the unit. There was no logical strategy connecting the patients required consultation sequence and the location of areas where the consultation would be conducted. Overlapping of movement pathways within the unit causes considerable problems. The group felt the $\mathrm{CHU}$ was generally not user-friendly.

\section{Discussion}

Experience based co-design and post occupancy evaluation, when used as a means to inform the design of built spaces, share a common strategy. They both incorporate the opinions of current or intended users regarding a built space. These opinions indicate whether or not the planned space does in fact reflect its end purpose. In the case of the hospital Cardiac Health Unit the relevant users include doctors, nursing staff, and patients (and family/friends).

Obtaining relevant and useful input from groups who have no design experience is problematic $[7,16,18]$. Design professionals are concerned that users are lacking in design conceptual knowledge and experience [10]. Yet the user is at the core of EBCD and POE analysis. Design strategies "need a deeper understanding of the problems and realities of people for whom we are designing" [9]. This study aimed to minimize the above perceived difficulty by providing users with a 'guideline' to express their opinions and experiences. The instrument used a structure based on elements of building functionality [4]. These elements were also linked to healthcare environmental variables based on EBD research [9]. The unique perspective of this instrument is its focus on the 'functionality' characteristics of the built environment.

The results of the initial survey, and later focus group discussions, elicited considerable relevant information. That the three participant groups (doctors, nurses, patients) clearly showed different response profiles suggesting the instrument is capable of tapping differences in perceptions. The end-point of the process (joint working group) resolved issues using the criteria specified in the instrument. The result is an overall perspective of the Cardiac Health Unit (CHU), rather than a comment on each of the contributing variables in isolation. The instrument fosters an integration of the users' various perspectives, thus giving an overall impression of the Cardiac Health Unit. The issues discussed in the focus groups, although related to healthcare environment variables, were nevertheless discussed in the context of the function of the CHU. Hence, the users were able to decide that amount of "physical space" available was a primary concern. Further, in regards to the feeling of confusion in the patients, the working group decided on a cause for this problem. The absence of a logical spatial layout connecting patient treatment flow and the location of the relevant treatment areas was considered the cause of patients' confusion. An analysis of the full outcome of the joint working group discussion provided valuable insights. By understanding the concerns of the users resulting from this assessment, design specialists will have a valuable set of inputs to inform their final building design.

Although the structured format for gathering user input was beneficial in providing focused guidelines for discussion, there was an issue that arose during the joint working group discussion. The relative status of participants has been identified as an issue [6,7]. In the early stages of the joint working group discussion, nurses and patients were observed deferring to doctors, and patients in turn deferring to nurses. However, after some pertinent comments the situation altered. In response to a doctor's comments, a senior nurse suggested that the doctor was not always present: "before you arrive" and "after you've gone" were the bases to her reply. The 
medical staff were seemingly more empathetic after a very senior patient explained the anxiety, fear, and confusion felt by most patients when they were at the CHU. After this exposition, the entire working group began to meld and focus on the discussion structure at hand: "We need to focus on the problems we have experienced so we can make positive suggestions" [Participant nurse comment]. A similar group dynamic was observed by Boström, Hillborg and Lilja (2017) when medical professionals and patients were involved in discussion groups. The authors observed that over the course of the meeting there develops a sense of mutual understanding and a trustful relationship.

A limitation of this current study may be that the small number of participants mitigates against any meaningful statistical analysis. However, results suggest that participant comments appear to be all encompassing. The inclusion of more users in each participant category, or in each step of the process, would most likely not identify any missed problem areas. It is possible, of course, that the strength of the observation (agree/disagree) may alter.

\section{Conclusions}

The aim of this study was to develop a suitable survey instrument to assess stakeholder feedback regarding a built environment. The results of the present study indicate that using a POE based, structured assessment strategy provides a solid guideline for determining a wide range of design issues from a user perspective. The strength and impact of the instrument is its ability to tap into a broad functional view of the users experience of a built environment. Its use has improved communication within user groups and will enhance subsequent discussion of built environment design variables with design specialists.

\section{REFERENCES}

[1] A. Brambilla, and Stefano Capolongo. (2019). Healthy and Sustainable Hospital Evaluation-A Review of POE Tools for Hospital Assessment in An Evidence-Based Design Framework. Buildings 9 (76): 1-22. https://doi.org/ 10.3390/buildings 9040076 .

[2] Center Health Design. (2019). Community Health Center Facility Evaluation Tool. Online available from https://www.healthdesign.org/community-health-center-faci lity-evaluation tool-pdf-version

[3] D. Clarke, F. Jones, R. Harris, and G. Robert. (2017). What Outcomes are Associated with Developing and Implementing Co-Produced Interventions in Acute Healthcare Settings? A Rapid Evidence Synthesis. British Medical Journal 7(7): 1-11. https://doi.org/10.1136/bmjopen $-2016-014650$

[4] D.J.M. Van der Voordt, H.B.R. Van Wegen. (2005).
Architecture in Use: An Introduction to The Programming Design and Evaluation of Buildings. London: Elsevier.

[5] F.E.P. Wolfgang, E.T. White, and H.Z. Rabinowitz. (2015). Post-Occupancy Evaluation. London: Routledge.

[6] J. Boström, H. Hillborg, and J. Lilja. (2017). Cultural Change of Applying User Involvement for Improving Healthcare Quality: A Review of The Impact on Attitudes, Values and Assumptions Among Healthcare Professionals and Users. Quality Innovation Prosperity 21 (3): 158-172. https://doi.org/10.12776/QIP.V21I3.922.

[7] J. Carthey. (2019). Interdisciplinary User Groups and The Design of Healthcare Facilities. Health Environments Research \& Design Journal 1: 1-27. https://doi.org/10.1177/ 1937586719843877

[8] J.F. Stichler, and C. Sandra. (2007). Preparing Nurses for A Leadership Role in Designing Healthcare. Facilities 37 (6): 257-260.

https://doi.org/10.1097/01.NNA.0000277726.84821.9b

[9] L. Fay, A. Carll-White, and J. Harrell. (2016). Coming Full Cycle: Linking POE Findings to Design Application. Health Environments Research \& Design Journal 10 (3): 1-16. https://doi.org/10.1177/1937586716672856

[10] M. Elf, P. Fröst, G. Lindahl, and H. Wijk. (2015). Shared Decision Making in Designing New Healthcare Environments-Time to Begin Improving Quality. Biomed Central Health Services Research 15: 144. https://doi.org/10.1186/s12913-015-0782-7

[11]P. Bate and G. Robert. (2006). Experience-Based Design: from Redesigning the System Around the Patient to Co-designing Services with the Patient. Quality and Safety in Health Care 15 (5): 307-310. https://doi.org/10.1136/qshc .2005 .016527 .

[12] P. Jellema, M. Annemans, and A. Heylighen. (2019). Researching and Designing Health Care Environments: A Systematized Review of Creative Research Methods. Qualitative Health Research 29 (2): 290-300. https://doi.org/10.1177/1049732318792227

[13] R. Hamilton. (2003). The Four Levels of Evidence Based Practice. Healthcare Design, March 3, 2020. https://www.healthcaredesignmagazine.com/architecture/fo ur-levels-evidence-based-practice/

[14] R. Ulrich, C. Zimring, X. Zhu, J. DuBose, H.B. Seo, Y.S. Choi, X. Quan and A. Joseph. (2008). A Review of The Research Literature on Evidence-Based Healthcare Design. Health Environments Research \& Design Journal 1 (3): 61-125. https://doi.org/10.1177/193758670800100306

[15] S. Prugsiganont, and P.A. Jensen. (2019). Identification of Space Management Problems in Public Hospitals: The Case of Maharaj Chiang Mai Hospital. Facilities 37 (7/8): 435-454.

https://doi.org/10.1186/s40064-016-3665-4.10.1108/F-01-2 018-0001.

[16] T. Dimopoulos-Bick, P. Dawda, L. Maher, R. Verma, and V. Palmer. (2018). Experience-Based Co-Design: Tackling Common Challenges. The Journal of Health Design 3 (1): 86-93. https://doi.org/10.21853/JHD.2018.46.

[17] T. Green, A. Bonner, L. Teleni, N. Bradford, L. Purtell, C. 
Douglas, P. Yates, M. MacAndrew, H.Y. Dao, and R.J. Chan. (2019). Use and Reporting of Experience-Based Codesign Studies in The Healthcare Setting: A Systematic Review. British Medical Journal Quality \& Safety 29 (1): 64-76.
[18] T. Waroonkun. (2019). An Investigation of Nursing Staff Input for The Co-Design of an Outpatient Department. Urbanism Architecture Constructions 10 (2): 113-122. 